\title{
Neurite óptica bilateral após infecção viral por dengue: relato de casos
}

\author{
Bilateral optic neuritis after dengue viral infection: case report
}

\author{
Ricardo Evangelista Marrocos de Aragão ${ }^{1}$ \\ Ieda Maria Alexandre Barreira ${ }^{2}$ \\ Livia Nogueira Costa Lima ${ }^{3}$ \\ Leonardo Portela Rabelo ${ }^{4}$ \\ Felipe Bezerra Alves Pereira ${ }^{5}$
}

Serviço de Oftalmologia do Hospital Universitário Walter Cantídio da Universidade Federal do Ceará - UFC Fortaleza (CE) - Brasil.

${ }^{1}$ Doutor, Preceptor de Retina e Vítreo da Residência Médica de Oftalmologia do Hospital Universitário Walter Cantídio da Universidade Federal do Ceará UFC - Fortaleza (CE) - Brasil.

${ }^{2}$ Especialista em Retina e Vítreo pela Universidade Federal de São Paulo - UNIFESP - São Paulo (SP) - Brasil.

${ }^{3}$ Residente ( $3^{\circ}$ ano) do Serviço de Oftalmologia do Hospital Universitário Walter Cantídio da UFC - Fortaleza (CE) - Brasil.

${ }^{4}$ Residente $\left(3^{\circ}\right.$ ano $)$ do Serviço de Oftalmologia do Hospital Universitário Walter Cantídio da UFC - Fortaleza (CE) - Brasil.

${ }^{5}$ Residente $\left(2^{\circ}\right.$ ano) do Serviço de Oftalmologia do Hospital Universitário Walter Cantídio da UFC - Fortaleza (CE) - Brasil.

Endereço para correspondência: Ricardo E. Marrocos de Aragão. Rua Osvaldo Cruz, 2.335 - Fortaleza (CE) Brasil - CEP 60125-151

E-mail: ricardomarrocos@yahoo.com

Nota Editorial: Depois de concluída a análise do artigo sob sigilo editorial e com a anuência do Dr. Mário Teruo Sato sobre a divulgação de seu nome como revisor, agradecemos sua participação neste processo.

\section{RESUMO}

Dengue é uma doença viral transmitida pelos mosquitos Aedes aegypti e Aedes albopictus. Apresenta distribuição geográfica bastante ampla, sendo epidêmica em alguns países. A apresentação clínica depende da idade e do estado imunológico do paciente, podendo se apresentar de forma assintomática como, dengue clássica, hemorrágica e até como choque. Têm sido descritas muitas manifestações oculares, entretanto, poucos relatos de manifestações neurológicas causada por dengue. Relatamos dois casos de neurite bilateral pós infecção por dengue. Ambos apresentavam baixa de acuidade visual bilateral, papilite e alterações no campo visual e evoluíram com desaparecimento dos sintomas e sinais espontaneamente sem uso de medicação.

Descritores: Dengue/complicações; Papilite; Neurite óptica/etiologia; Hemorragia retiniana; Encefalite; Infecçồes oculares virais; Relatos de casos

\section{INTRODUÇÃO}

A dengue é uma infecção viral transmitida pela fêmea dos mosquitos $A$. aegypti e A. albopictus que tem hábitos diurnos. O vírus da dengue é da família Flavirida, arbovírus grupo B, sendo identificados 4 sorotipos (1, 2, 3 e 4). Com distribuição geográfica em mais de 100 países nos trópicos e subtrópicos incluindo América, sudeste da Ásia, oeste do Pacifico, África e leste do Mediterrâneo.

No Brasil, desde 1986 vêm ocorrendo epidemias de dengue, com cerca de 3 milhões de casos. Embora ocorra em todo o território nacional, entre os lugares de maior ocorrência, podemos citar os estados do Rio de Janeiro, Ceará, Alagoas e Pernambuco.

A dengue pode se manifestar de várias formas desde um simples resfriado a uma febre hemorrágica e choque, ameaçando a vida. As características clínicas da infecção viral por dengue podem ser classificadas em cinco apresentações: doença febril não específica, dengue clássica, febre hemorrágica por dengue, febre hemorrágica por dengue com síndrome do choque, e outras síndromes não usuais como encefalopatia e hepatite ${ }^{(1)}$. Há poucos relatos das manifestações neurológicas da dengue. O envolvimento do sistema nervoso central (SNC) tem sido descrito em pacientes pediátricos que algumas vezes podem se apresentar com encefalites graves. O envolvimento neurológico na infecção por dengue pode ser visto após a doença aguda ter cedido e acredita-se que seja uma manifestação imunomediada $^{(2)}$. Têm sido descritas algumas manifestações oculares na dengue, entre elas as mais comuns são: dor retrorbitária(3), hemorragias retinianas, hemorragia subconjuntival ${ }^{(4)}$; já manifestações como neurite óp- 
tica $^{(5)}$, maculopatia exsudativa ${ }^{(6)}$, efusão coroidal $^{(7)}$, manchas de $\operatorname{Roth}^{(8)}$, vasculite, descolamento de retina exsudativo e uveíte anterior são $\operatorname{raras}^{(9)}$. Descrevemos dois casos que apresentavam baixa de acuidade visual, papilite e alterações de campo visual pós infecção viral por dengue.

\section{RELATO DOS CASOS}

\section{Caso 1}

F.S.H., 31 anos, masculino, com história de dengue clássica há duas semanas, apresentou-se com queixa de baixa da acuidade visual em ambos os olhos (AO) mais importante no olho esquerdo. Ao exame oftalmológico, a acuidade visual (AV) era 20/30 no olho direito (OD) e conta dedos a um metro no olho esquerdo (OE); motilidade ocular extrínseca normal; presença de defeito pupilar aferente relativo no $\mathrm{OE}$; biomicroscopia normal; pressão intraocular normal em $\mathrm{AO}$ e à oftalmoscopia binocular indireta edema do disco óptico bilateral (Figura 1); campo visual evidenciando escotomas cecocentrais. Os exames complementares como tomografia computadorizada do crânio, pressão arterial, glicemia de jejum e VHS estavam normais; FTA-ABS e sorologia para HIV estavam negativos e a sorologia para dengue pelo método imunocromatográfico foi positiva (IgG e IgM reagentes). Pesquisa do líquor cefalorraquidiano revelou líquor claro com glicose, proteínas, contagem de células e diferencial normais e pressão liquórica normal.

Paciente evoluiu com melhora da AV em um mês e apresentou regressão da papilite com recuperação da AV para 20/20 em AO.

\section{Caso 2}

B.S.O., 14 anos, masculino, com história de dengue há duas semanas, apresentava queixa de baixa da acuidade visual em AO mais intensa no OE. Ao exame oftalmológico, apresentava acuidade visual corrigida 20/125 no OD e no OE 20/200 e defeito do reflexo pupilar aferente relativo no OE. A motilidade ocular extrínseca, biomicroscopia do segmento anterior e pressão intraocular normais em AO. Ao exame de fundo de olho apresentava edema do disco óptico com hemorragias peridiscais bilateral (Figura 2). O campo visual mostrava escotomas cecocentrais em AO. Os exames complementares mostraram: Tomografia computadorizada do crânio, pressão arterial normais, proteína $C$ reativa, anticorpo antifosfolipídio e anticardiolipina, VHS e FTA-ABS negativos. Sorologia positiva para dengue pelo método imunocromatográfico IgG e IgM reagentes; líquor e pressão liquórica normais. O paciente evoluiu com melhora da AV para 20/60 no OD e 20/50 no OE doze dias após o exame inicial e posteriormente normalizou a AV com regressão dos achados oftalmoscópicos.

\section{COMENTÁRIOS}

Dengue é uma virose transmitida pelo mosquito Aedes aegypti que pica apenas durante o dia, ao contrário do mosquito comum (Culex), que pica à noite. A infecção pode ser causada por qualquer um dos quatro tipos $(1,2,3$ e 4$)$ do vírus da dengue, que produzem as mesmas manifestações. Em geral, o início é súbito com febre alta, dor de cabeça e muita dor no corpo. É comum a sensação de intenso cansaço, a falta de apetite e, por vezes, náuseas e vômitos. Pode ocorrer eritema com manchas, semelhantes às do sarampo ou da rubéola, e prurido no corpo. Pode ocorrer, às vezes, algum tipo de sangramento (em geral no nariz ou nas gengivas).

O diagnóstico de dengue é clínico. A sorologia deve ser feita principalmente para controle da vigilância epidemiológica, pois em geral é inútil na condução do tratamento. O ideal é colher após sete dias do início dos sintomas. Anticorpos do tipo IgM contra o vírus da dengue são detectáveis desde o $6^{\circ}$ dia e perduram até 90 dias, já o IgG pode ser
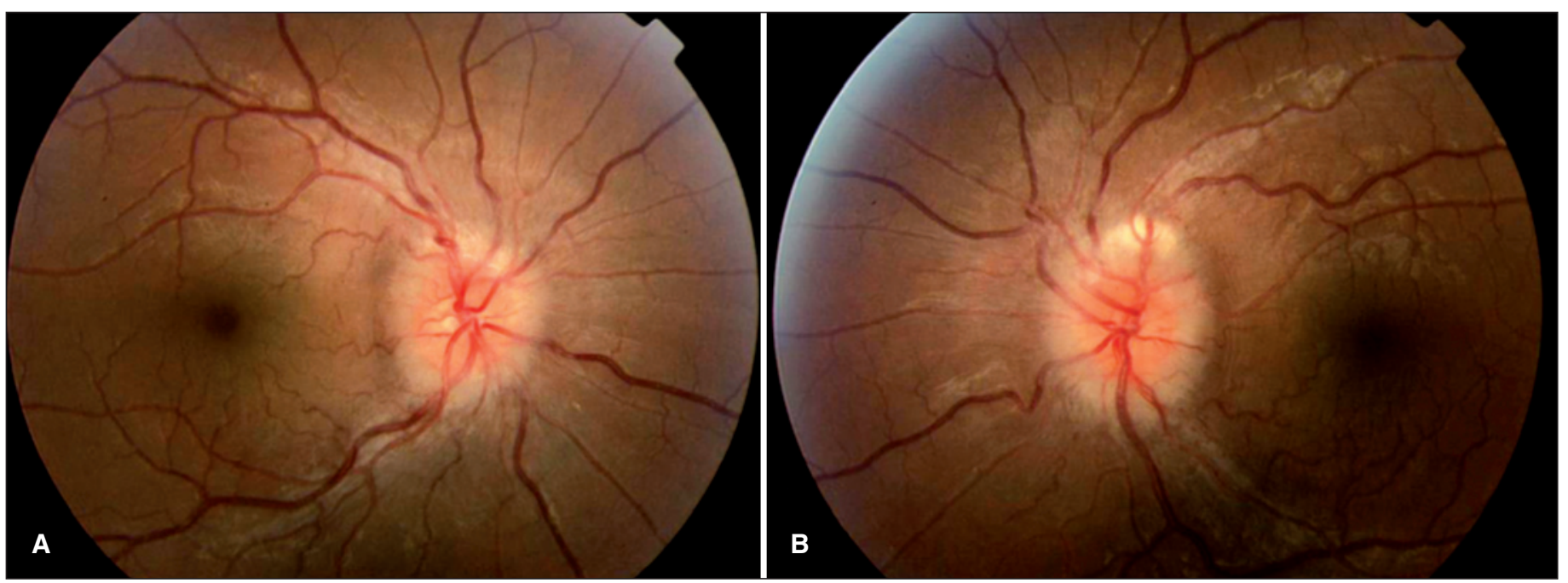

Figura 1 - Caso 1: Edema bilateral do disco óptico (A - olho direito e B - olho esquerdo) 

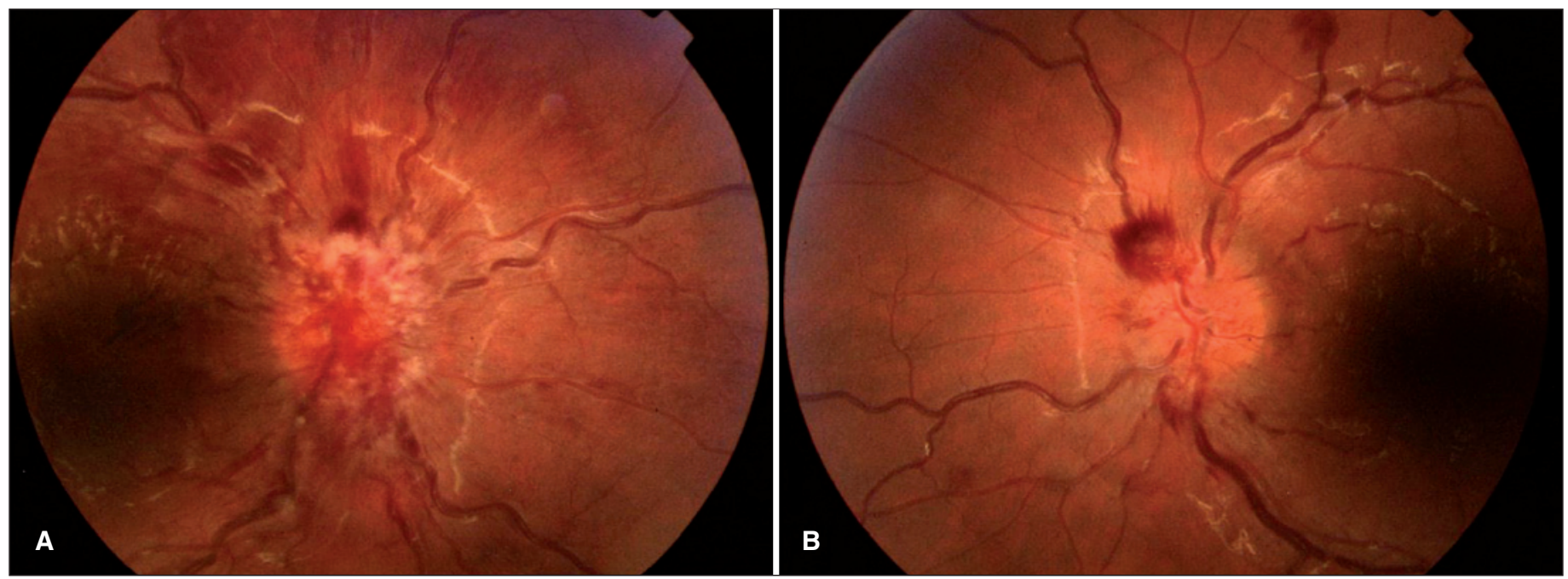

Figura 2 - Edema bilateral do disco óptico com hemorragias peridiscais (A - olho direito e B - olho esquerdo)

detectado nos primeiros dias da doença até dois ou três dias após a infecção.

As principais alterações oculares reportadas na literatura relacionadas à dengue incluem hemorragias na retina e mácula, hemorragia peridiscal, manchas de Roth, edema retiniano difuso, células no vítreo, borramento da margem do disco óptico, descolamento seroso da retina, efusão coroidal e maculopatia não específica ${ }^{(1)}$. A neurite óptica é um processo inflamatório, infeccioso ou desmielinizante do nervo óptico que pode se manifestar como neurite retrobulbar, papilite ou neurorretinite. A papilite é caracterizada por hiperemia variável e edema do disco óptico que pode estar associado a hemorragias peripapilares em chama de vela. A papilite pode ser secundária a infecções virais (neurite óptica parainfecciosa) e provavelmente ocorre devido à resposta imunológica. Tipicamente, manifesta-se uma a três semanas após infecção viral com perda aguda e grave da AV que pode ser bilateral, porém o prognóstico visual é surpreendentemente bom, mesmo na presença de edema importante do disco óptico. A recuperação espontânea da visão pode ocorrer, dispensando tratamento na maioria dos pacientes acometidos. Nos casos refratários o uso de corticóide oral passa a ser uma opção de tratamento, uma vez que a neurite óptica provavelmente ocorre devido à reação imunológica, mas seu uso é controverso.

Nos casos relatados, o diagnóstico diferencial com papiledema é de essencial importância tanto para a conduta como para o prognóstico.

Papiledema é o edema bilateral da cabeça do nervo óptico, secundário à elevação da pressão intracraniana, geralmente devido à presença de massa intracraniana. A medida da pressão liquórica e métodos de neuroimagem, particularmente a ressonância magnética que permite detectar lesões da parte intraorbitária do nervo óptico (por exemplo: neurite, glioma), bem como a extensão intracraniana de tumores do nervo óptico são de especial valor. Nos casos em questão, optamos por fazer tomografia devido ao fato de ser o exame disponível em nosso serviço, ao fato de a pressão liquórica dos pacientes ser normal e a evolução de ambos os casos ter sido favorável.

As manifestações neurológicas da dengue são raras e por não serem típicas da dengue, os pacientes foram avaliados detalhadamente para determinar a causa da neurite. Como ambos os pacientes apresentavam sorologia positiva para dengue sem nenhuma outra causa aparente de neurite e também pelo fato de a neurite ter resolvido espontaneamente, como pode ocorrer em doenças virais, concluímos que nos casos expostos, a neurite óptica resultou da infecção pelo vírus da dengue (neurite óptica parainfecciosa). O exame do fundo de olho tem sido recomendado em casos graves da doença, pois, particularmente nas áreas endêmicas, se mais exames do fundo de olho fossem feitos nos estágios precoces em pacientes com suspeita de dengue, muitos casos de envolvimento do SNC poderiam ser detectados e manejados apropriadamente ${ }^{(2)}$. O prognóstico é geralmente bom e resolvendo espontaneamente, embora alguns pacientes possam referir escotoma central relativo que pode persistir por meses. O uso de esteróides para tratar as alterações visuais é controverso ${ }^{(9)}$.

Com aumento da epidemicidade e a existência de múltiplos sorotipos da dengue, é esperado um aumento de casos de dengue tanto na forma clássica como hemorrágica com provável aumento da morbidade ocular e sistêmica, por isso, medidas de profilaxia, como eliminar os focos de reprodução, retirando água parada no interior de garrafas, pneus e vasos, tampando caixas d'águas; usando telas protetoras em janelas e portas para impedir o acesso do mosquito e usando inseticidas e desinfetantes para diminuir a presença dos mosquitos são essenciais e devem ser amplamente divulgadas diminuindo assim, o risco de contágio e consequentemente os prejuízos que a doença pode acarretar. 


\section{ABSTRACT}

Dengue fever is a well known viral infection transmitted through the bite of an infected Aedes aegypti and Aedes albopictus mosquito. Its geographic distribution covers over 100 countries. Clinical presentation is variable and depends upon the age and immunological status of the patient. It can be classified as asymptomatic illness, dengue fever, dengue hemorrhagic or dengue shock syndrome. Ocular manifestations of dengue have been described, however there are few reports on neurological involvement. We hereby report two cases of bilateral optic neuritis after dengue viral infection. Both of them rapidly recovered the visual acuity without treatment.

Keywords: Dengue/complications; Optic neuritis/etiology; Papilledema; Retinal hemorrhage; Encephalitis; Ocular infections, viral; Case report

\section{REFERÊNCIAS}

1. Lim WK, Mathur R, Koh A, Yeoh R, Chee SP. Ocular manifestations of dengue fever. Ophthalmology. 2004;111(11):2057-64.

2. Angibaud G, Luaute J, Laille M, Gaultier C. Brain involvement in Dengue fever. J Clin Neurosci. 2001;8(1):63-5.

3. Haritoglou C, Scholz F, Bialasiewicz A, Klauss V. Okuläre Manifestation bei Dengue-Fieber. Ophthalmologe. 2000;97(6):433-6.

4. Gill WD. Ocular symptoms in dengue based on analysis of 1241 cases. Arch Ophthalmol. 1928;57:628-38.

5. Preechawat $P$, Poonyathalang A. Bilateral optic neuritis after dengue viral infection. J Neuroophthalmol. 2005;25(1):51-2.

6. Haritoglou C, Dotse SD, Rudolph G, Stephan CM, Thurau SR, Klauss V. A tourist with dengue fever and visual loss. Lancet. 2002;360(9339):1070. Comment in: Lancet. 2003;361(9352):181-2.

7. Cruz-Villegas V, Berrocal AM, Davis JL. Bilateral choroidal effusions associated with dengue fever. Retina. 2003;23(4):576-8.

8. Shubhakaran Jakhar R. Ocular changes in infectious diseases. J Assoc Physicians India. 2005;53:913-4; author reply 914.

9. Chan DP, Teoh SC, Tan CS, Nah GK, Rajagopalan R, Prabhakaragupta MK, Chee CK, Lim TH, Goh KY; Eye Institute Dengue-Related Ophthalmic Complications Workgroup. Ophthalmic complications of dengue. Emerg Infect Dis. 2006;12(2):285-9. 